\title{
Erratum
}

(Sādhanā, Vol. 29, No. 2, April 2004, pp. 299-308)

\section{Bayesian and Dempster-Shafer fusion}

\author{
SUBHASH CHALLA and DON KOKS
}

(1) The paper "Bayesian and Dempster-Shafer fusion" contains a mistake in Appendix A, although this has not affected anything in the body of the paper. On page 172, the authors state correctly that the matrix $F$ is, in general, not square, but then in (A.22) they take its determinant. This confusion resulted because the theorem being proved was used twice in the report, once when $F$ was square, and once when it was not.

Theorem 1 is unchanged. Theorem 2 still holds; its corrected proof is somewhat longer, and has been rewritten fully so that the new version [now on the internet] is self contained.

There were also some typographical errors in the original paper. The references to (3.18) and (3.22) in equation (28) did not exist in the original paper and have been corrected in the current on-line version. Also, on page 165 on the fifth line of text, the subset printed as " $\{$ Learjet, Falcon, $\}$ " should be " $\{$ Learjet, Falcon, Caravan\}".

(2) The full corrected version of the paper can be found on the Sadhana web site 